\title{
PSYCHE
}

\begin{tabular}{lll} 
Vol. 70 & December, 1963 & No. 4 \\
\hline
\end{tabular}

\section{A NEW GENUS AND SPECIES OF NEOTROPICAL HORSEFLY (DIPTERA: TABANIDAE)*}

\author{
By G. B. FaIrchild
}

Gorgas Memorial Laboratory, Panama, R. de P.

The Neotropical Tabanidae are remarkable for the number of bizarre forms which have developed, especially in the Tribe Diachlorini. Of the 146 generic names proposed at one time or another to include Neotropical Tabanidae, 65 were proposed for Diachlorini. The mortality rate among these names has been high, and conservative students of the family will probably recognize hardly half of these as useful. The proposal of another new genus in this fauna may thus appear somewhat foolhardy; nevertheless, the subject of this note presents a so far unique combination of characters which disturbs current ideas as to relationships within the Tribe.

Querbetia gen. nov.

Eyes bare, apparently with green bands in life. Frons broad, less than twice as high as basal width, with basal callus as wide as frons. Vertex with vestiges of ocelli. Antennae with first segment very greatly inflated and shiny, second segment short and normal, third segment lacking in the only known specimen. Proboscis with theca and labella extensively sclerotized and shiny. Wing venation normal, the subepaulet or basicosta lacking strong setae. Abdomen with second segment narrowed, giving a wasp-waisted appearance. Legs without hind tibial spurs or hind tibial fringes. The name is an anagram of that of Dr. Joseph Bequaert and is masculine. Type and sole species of the genus, Querbetia bequaerti n. sp., described below.

\section{Querbetia bequaerti n. sp.}

A blackish wasp-like insect with greatly inflated and shiny subcallus and basal antennal segments, constricted abdomen and wings with anterior half black.

\footnotetext{
*Manuscript received by the editor June 10, 1963.
} 

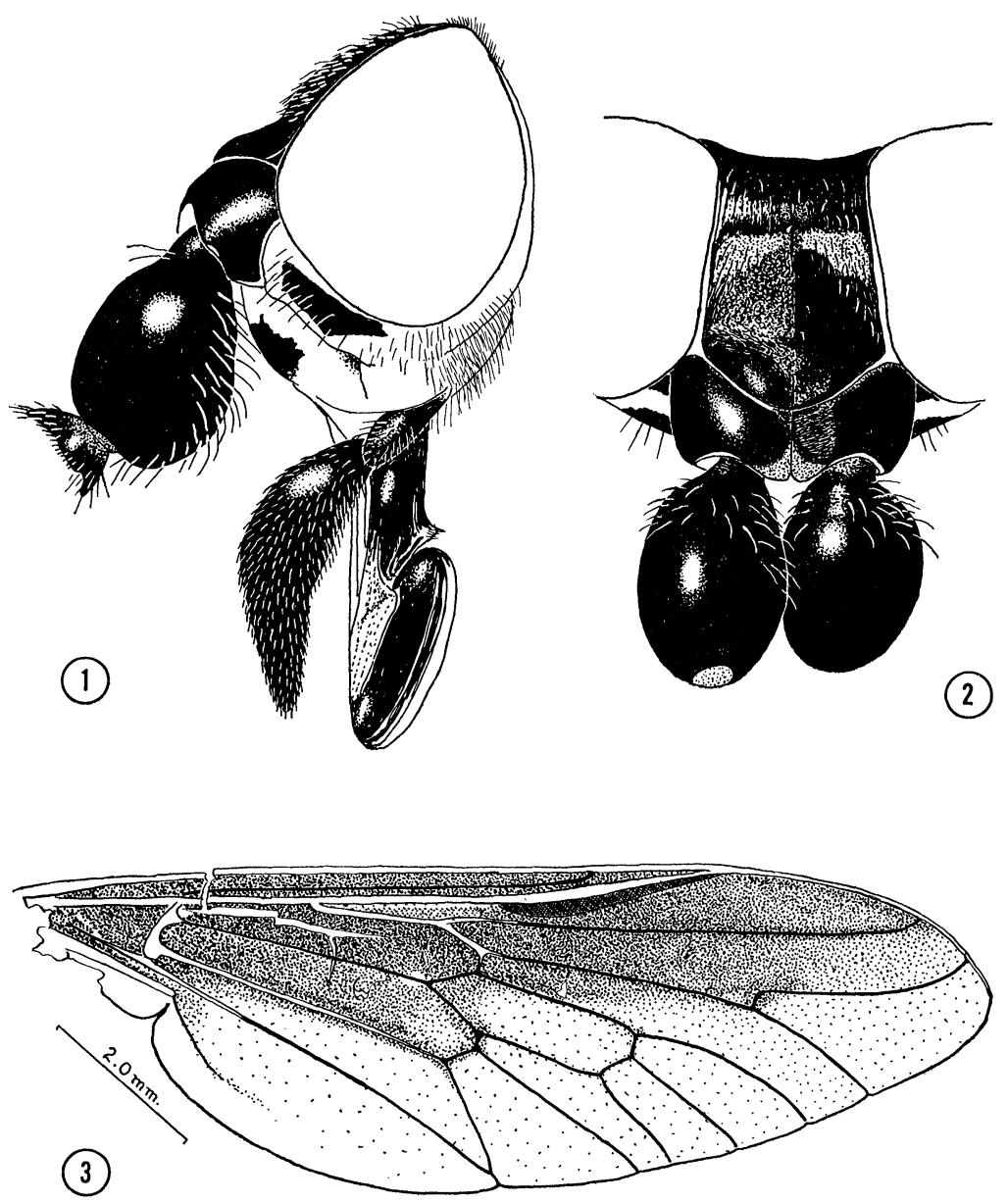

FAirchitd - Querbetia 
Female. Length, I $4 \mathrm{~mm}$., of wing, $\mathrm{I} 2 \mathrm{~mm}$. Eyes bare. Efforts to revive the eye pattern were not wholly successful, but suggest that the eye was probably green with two narrow parallel transverse dark bands. Frons slightly higher than basal width, narrowed above. Callus black, rugose, nearly filling lower half of frons, and leaving but two small thinly yellowish pollinose triangular areas separating callus from the wholly black and shiny vertex. Vestiges of three ocelli are visible close to the lower margin of the shiny area of vertex. Subcallus greatly inflated, black and shiny, with a strong median groove dividing it into two hemispherical halves. Fronto-clypeus and genae thinly yellowish pollinose, with a roughly wineglass-shaped bare area in center of fronto-clypeus, and large bare patches on genae, both bare areas dark brown to black. First antennal segments enormously inflated, black and shiny with sparse long hairs at base and on ventral surface. Second segment black and shiny, not inflated, with a strong dorsal spur and numerous black hairs. Third segment missing. Palpi black, subshiny, black-haired dorsally, longer ventral hairs brownish yellow. Proboscis black, the theca and a broad basal strip of labella sclerotized, shiny.

Mesonotum blackish in ground color, subshiny to thinly grey pollinose, with the sides and humeral callosities reddish, and a pair of dull reddish dorsolateral stripes. Vestiture of sparse black hairs, with some reddish brown hairs accentuating the dorsolateral stripes. Pleura blackish brown, thinly grey pollinose, sparsely dark-haired. Scutellum black, with black and sparse pale hairs. Legs black, black-haired, the basal thirds of all tibiae yellowish white, white-haired, the tarsi yellow and yellow-haired. No hind tibial fringe. No spurs on hind tibiae. Wing as figured, the basicosta bare, the dark portions deep brownish black, the clear portions yellowish tinged.

Abdomen slender, the second segment slightly narrowed, the tergites dark brown, their posterior margins very narrowly yellowish. $V$ estiture of thin greyish pruinosity and sparse hairs, mixed black and yellowish, without noticeable pattern. Venter as dorsal surface, except that first four sternites are more densely white-haired, fifth and succeeding sternites dark reddish-haired.

Holotype female, Tingo Maria (Rio Huallaga) Peru, 700 M., Aug. 1947, leg. Weyrauch. In Museum of Comparative Zoology. The abdomen is intact, though detached and glued to a card below the

\section{Explanation of Plate 20}

Querbetia bequaerti, n. sp. Fig. 1. Head in side view. Fig. 2. Frons and basal antennal segments. Fig. 3. Wing. 
specimen. One wing was also so glued, but has been mounted in Euparal on a microscope slide. The generic name is an anagram of that of Dr. Joseph Bequaert, to whom this remarkable genus and its included species are respectfully dedicated.

The relationships of this genus appear to be closest to Acanthocera, with which it agrees in general facies, wing pattern, shape of frons, etc., but from which it differs most markedly in the inflated subcallus and first antennal segments. The lack of terminal antennal segments in the only known specimen makes detailed comparison unprofitable. The only other genera of Neotropical Tabaninae with such inflated first antennal segments are Bolbodimyia Big. and Oopelma End. From Bolbodimyia the present genus differs in wasplike fascies, different wing pattern, shiny areas on frontoclypeus and genae, lack of inflated tibiae or hind tibial fringe, normal venation ( $\mathrm{R} 2+3$ not bent abruptly forward), and presence of marked vestiges of ocelli. From Oopelma it differs in much greater size, Oopelma being a tiny Tabanid less than $7 \mathrm{~mm}$. long, in not having the cross-veins prominently clouded, and in having shiny inflated palps and sclerotized theca and labella of the proboscis.

Oopelma appears to be an extreme development of tendencies foreshadowed in certain species of Stenotabanus, e.g. St. liokylon Fchld., which have the first antennal segments bare and shiny, though very little inflated. It would appear that development of the greatly inflated basal antennal segments has taken place independently in these three genera of Diachlorini, and is unlikely to be of phylogenetic significance. 

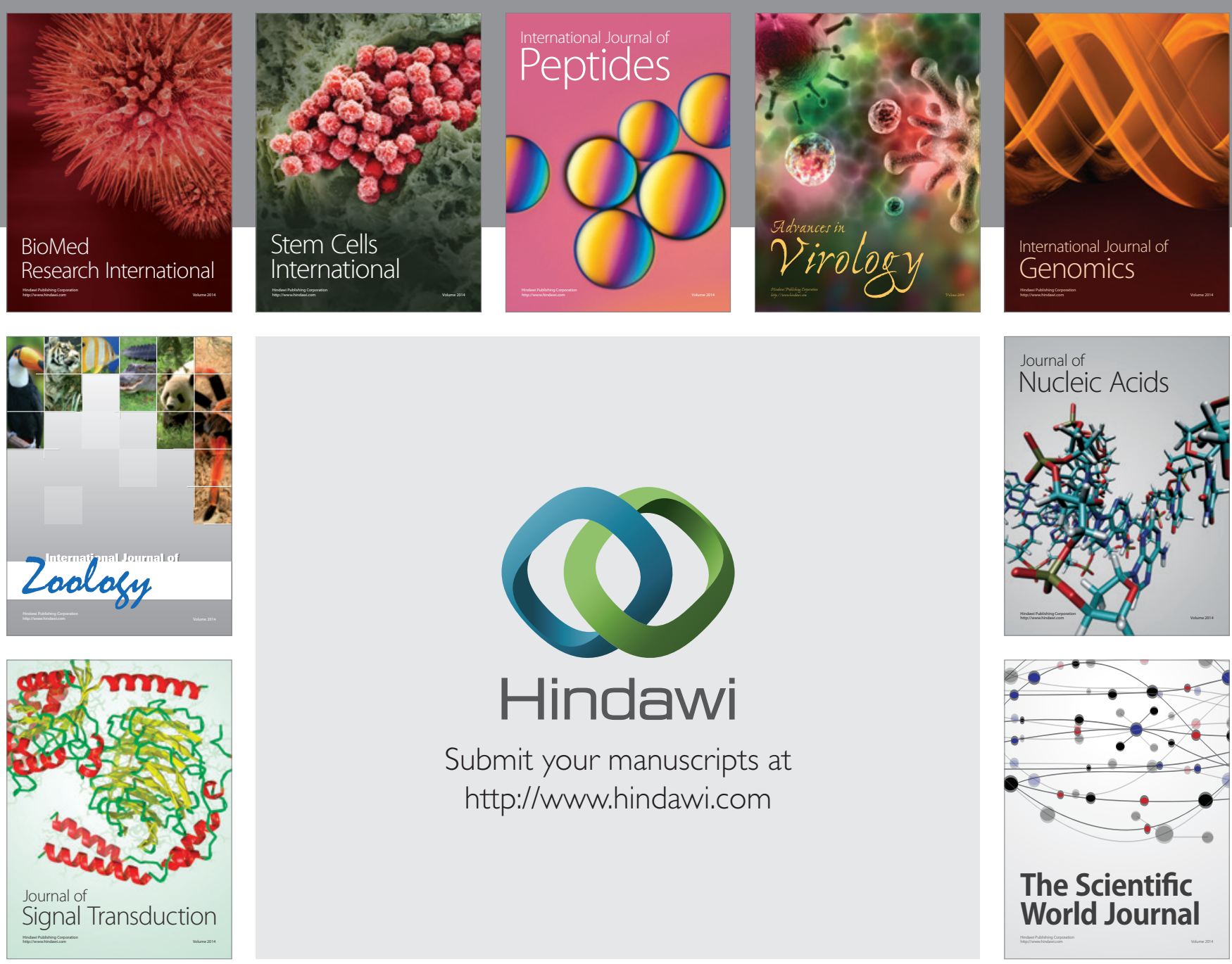

Submit your manuscripts at

http://www.hindawi.com
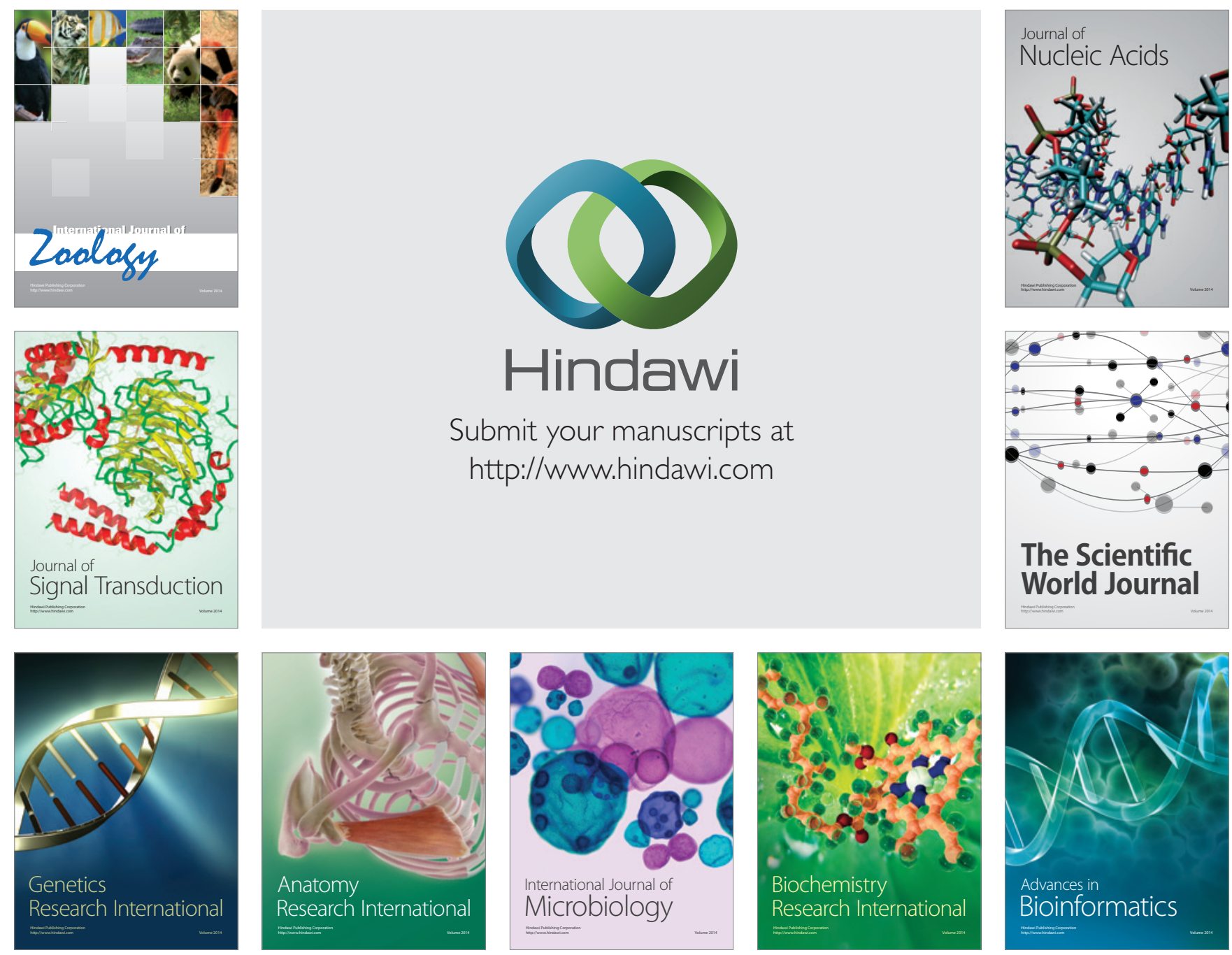

The Scientific World Journal
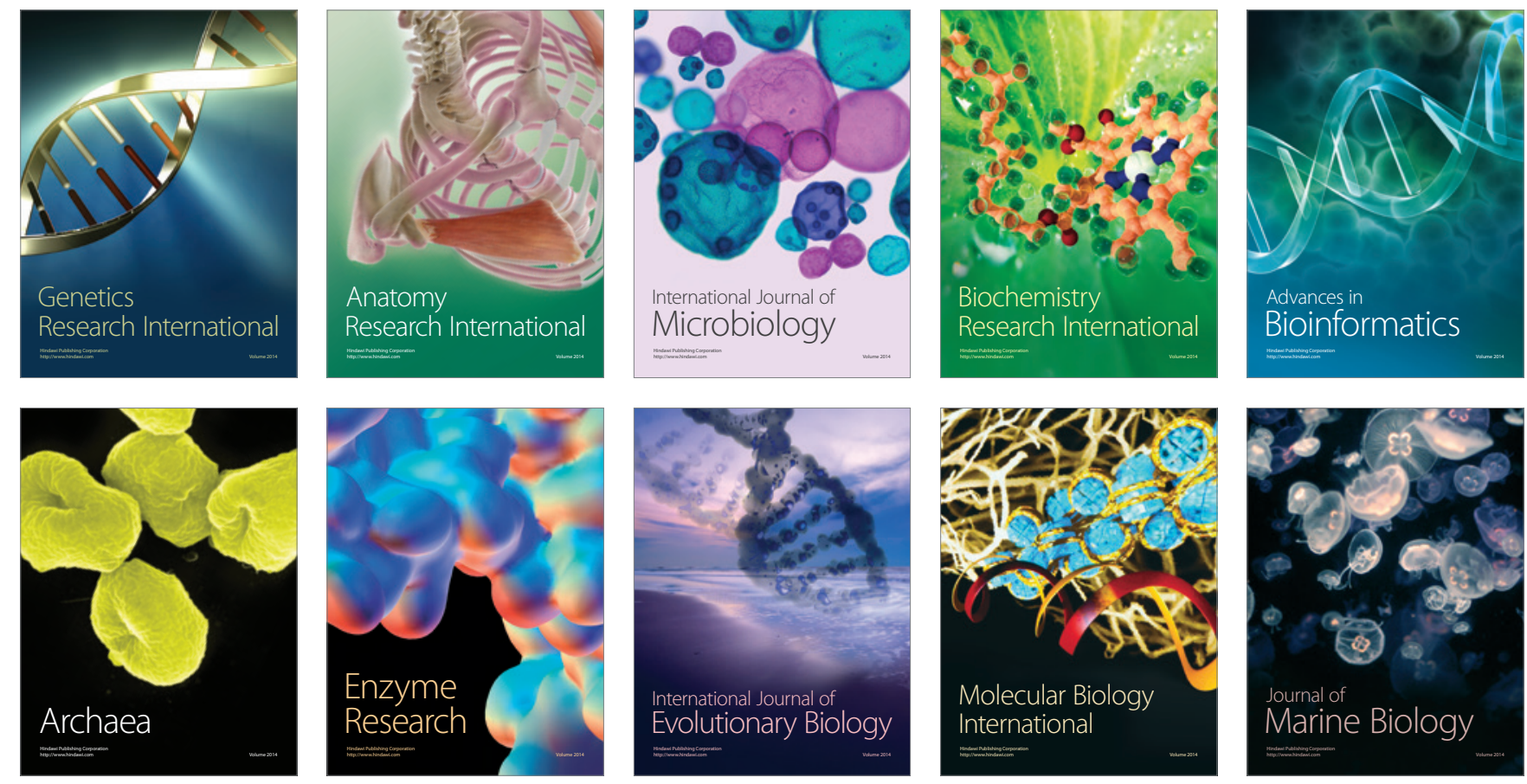